\title{
John Kirkup: A history of limb amputation [print/digital]
}

\author{
Springer Verlag, London, Springer, Paris, Berlin, Heidelberg, New York, 2007, 192 pp.; \\ 99 figs. Hardcover, EUR 149,95, CHF 261,50 USD 169,00, GBP 100,00, \\ ISBN: 978-1-84628-443-4/1846285097/1846284430/9781846285097
}

\section{Pierre Kehr}

Received: 1 May 2010/Accepted: 5 May 2010/Published online: 19 May 2010

(C) Springer-Verlag 2010

What a strange idea to write (and publish...) a book about limb amputation at the beginning of the twenty-first century. Amputation is generally considered as a dramatic treatment failure, and most of surgeons do not like to speak about such procedures. However, especially in trauma centers or referral centers, there are still some patients where amputation is required or at least indicated and discussed.

After a description of the more common causes for amputation of the limbs, the author analyses more extensively the different causes:- trauma cases of various etiologies,-ritual, punitive, legal amputation,-_iatrogenic causes, - war amputations. All these items are analyzed from the historical point of view, assuming that most causes have now disappeared in the western countries.

The next sections deal with the history of elective amputation from Hippocrates to our modern times. It is quite interesting to learn, how amputations was indicated and performed, with some awful instruments or techniques, mostly without any anesthesia.

A philosophical section deals with the interpretation of amputation by the society, the patients and the surgeons. Finally, some considerations about stump disorders, rehabilitation and development of artificial limbs bring some more optimistic sight.

A very uncommon book, but bringing some interesting overview along the history of surgery.

Dr. Jean-Yves Jenny Strasbourg

No funds were received in support of this study.
P. Kehr $(\bowtie)$

SOTEST, Strasbourg, France

e-mail: kehrpier@aol.com 